\title{
Information Technologies in Educational Sphere: Challenges and Risks*
}

\author{
Ekaterina Gnatik \\ Department of Ontology and Epistemology \\ RUDN University \\ 6 Miklukho-Maklaya Str. \\ Moscow, Russia \\ E-mail: ekaterinagnatik@ rambler.ru
}

\begin{abstract}
The article is devoted to the analysis of changes taking place in the sphere of the higher education. It is noted that the use of computer technologies is a subject to a significant transformation in not only communicative, but also mental, motivational and emotional spheres of the society. New information technologies significantly transform the framework of the traditional educational process, creating not only new opportunities, but also new problems. Multimedia means while increasing the scales of new knowledge significantly change the nature of their receiving radically. It is emphasized that informatization is a serious challenge to the Pedagogical Science and the educational system as a whole.
\end{abstract}

Keywords-IT; communication technologies; cyber space; cognitive abilities; electronic educational resources; traditional education system; computer-oriented education system

\section{INTRODUCTION}

The new global culture has a significant impact on the modern educational environment, focusing it on compliance with the standards of the IT-age. Technologies have already firmly embedded in the education system, giving new opportunities, sources of information, the format of classes and the system of expectations. The use of multimedia training courses, simulators, web-seminars, teleconferences and other information and communication technologies makes significant changes in the content and organization of the educational process, and therefore it affects the quality of educating professionals. Currently, there is a restructuring and development of the indicative and also operational and technical aspects of training, what is changing the spatial and time boundaries for interaction of participants in the process. The so-called Learning Management System (LMS) are actively implemented in Higher education institutions. In fact, the technocratic approach to education has been officially declared. Based on the application of the competence approach, various electronic educational resources, testing systems, personal student rankings, etc., as well as on using strictly regulated reporting documentation, it is planned to include national education of Russia in the global system. By and large, IT-technologies as new communication tools of mediation are focused on maximum monitoring,

* The publication has been prepared with the support of the "RUDN University Program 5-100" predictability and total controllability of the education process.

The study of the specificity of the information culture impact on this important sphere of human activity faces many difficulties. One of them is that the educational process, like other processes of self-organization, contains elements of unpredictability. Certainly, the problem of informatization of education cannot only be considered as instrumental and technological or as a problem of saturation of the sphere of education by means of Computer Science and pedagogical tools created on their basis. Nowadays we need systematic and unbiased research to answer the question of whether information technology can be a highly effective means of supporting the educational process.

\section{QUALITATIVE RESTRUCTURING OF THE \\ EDUCATIONAL SYSTEM AND CHANGING THE NATURE OF RECEIVING NEW KNOWLEDGE}

The current generation of university students belongs to the so-called digital generation, characterized by a special way of world perception and the possibility of parallel existence in the real and digital worlds. There are more and more facts showing that the use of computer technology is making a significant transformation of not only communicative, but also mental, motivational and emotional spheres of a person [1]. E-learning resources are steadily becoming a very important and even decisive element in the education space. New information technologies significantly transform the framework of the traditional educational process, creating not only new opportunities, but also new problems. Multimedia means while increasing the scales of new knowledge significantly change the nature of their receiving radically. There is a reason to believe that Informatization, by stimulating the "most convenient" for formalization activities, contributes to the gradual extinction of "competing" ways of cognition. Thus, easy access to information displaces self-development of new knowledge with its inherent reflection and comparative analysis. Information is usually transmitted in "ready to use" form, i.e. it has already been carefully processed and packed. According to experts, "it is important to distinguish between information (a wide range of facts) and knowledge (the result 
of reflection and cognitive processing, integration and evaluation): there are a lot of the first and often too little of the second in technologies. ... The danger is in perception technology not as a tool, as a source of raw material, but as the content and the final product of the educational process" [2]. It is stated that the earlier there is an involvement into processes of using Network, the "greater is the extent a person can be accustomed to absorb prepared estimates, judgments and conclusions. A young man "swallows" processed ("inanimate") information that does not require self-analysis and individual assessment" [3].

Bologna process proclaimed a strategy of rationalization of the Higher education. Of course, rationality should be manifested not only in the external forms of the organization, but also in the formation rational thinking among students. However, the results of monitoring the intellectual development of schoolchildren and students demonstrate that currently less than $20 \%$ of young people have a full-fledged conceptual thinking. That is, becoming hostages of the digital world, people lose the ability to think, analyze, make decisions on their own. It has become absolutely a commonplace for modern students to use materials taken from WEB-sites as the final and qualified source of information. As a result, there is easy and abundant "semifinished products" of knowledge in information environment. This leads to a "gap between knowledge and the experience of cognition": "the experience of cognition, laid down in the classical procedure of referencing (working with the text, reconstruction of content), is nullified in this case" [4]. That is, in this situation, there are no attributes of labor-intensive specific research activities that contribute to the formation of the necessary skills. In addition, interactivity, brightness of the technologies used in the learning process often stimulates the expectation of entertainment instead of interest in obtaining knowledge. There is a very high risk of getting used to the imitation, game character of activity. As a result, a student is involved into the process, but he or she is not able to learn something new and useful from it. This is very reminiscent of the same postmodern simulacrum "something that doesn't have its own content, but quite convincingly imitates certain entities actualized for a particular subject" [5]. Such activity cannot promote mastering educational material and cannot lead to positive results neither for development of the student personality, nor for improvement of educational process.

\section{TECHNOLOGICAL ModificAtion OF MENTAL AND COGNITIVE FUNCTIONS}

Technological transformation of cognitive and mental functions is gaining momentum. The experience gained over the past few years shows that Internet resources form a fundamentally new environment for the development and functioning of mental processes. There is a growing number of scientific publications indicating that the active use of ITdevices in educational activities by students affects the indicators of verbal intelligence. The most frequently noted undesirable effects on cognitive abilities are: a low level of concentration, memory impairment, inability to understand linear text and hierarchical relationships. It is stated that the students who systematically use a computer to perform educational tasks and watch movies demonstrate a lower level of conceptual thinking and a less developed reading skill. The conclusion of experts is: "Usage of IT technologies in education in the forms it takes place nowadays, at least does not contribute to the development of verbal intelligence" [6]. The process of replacing traditional paper books with electronic media has negative consequences. The results of the research suggest that under the influence of information and communication technologies, our perception becomes more superficial. Practicing German psychiatrist M. Spitzer notes: "Previously, the texts were read, today they are viewed fluently, that is, gallop them fluently. Earlier we dived into the topic and today they surf the Internet instead (i.e. skim the surface of information)" [7]. The conclusion of the scientist is unambiguous: "The more superficially I delve into the essence of the information received, the fewer synapses will be activated in my brain, therefore, I will remember it badly. Understanding of it is crucial because it is for this reason that digital media, communication networks and the Internet have a negative impact on learning" [8].

The traditional system implements the joint verbal and logical method of teaching. It means that it is significantly less based on the visibility of the educational material in the educational process than the computer-oriented system. Orientation to the possibilities of new tools and information technologies inevitably leads to the visualization of the disciplines content [9]. It is possible that the image can gradually become the central construct of a modern man thinking [10]. As a result, the need for systematic knowledge is replaced by fragmented information. This generates reluctance to read, inability to concentrate, analyze, generalize. The process of forming visual dominant of thinking is almost imperceptible, and children and young people are particularly vulnerable to it. On the basis of psychological analysis, the possibility of technology influence on changes in the processes of human identification is also revealed. In particular, the specific impact on human personality is considered within the framework of the problem defined as "simultaneous actualization of "parallel" identities" [11]. It is known, that information technologies provide users with the ability to support "many windows open." For instance, students can simultaneously perform several roles or quickly change them (for example, to attend lectures and chat with friends online, to drive a car and watch a video, etc.). Thus, one context can be replaced by another at any moment. Experts say that this leads to instability of identities, easiness in ignoring the contradictions between them (otherwise a person would constantly experience an internal conflict) [12].

Internet inexorably becomes the dominant infrastructure of knowledge. In our opinion, can be justified fears of reduction and depersonalization of communication associated with the gradual extinction of the role of emotions in traditional communication, taking place under the direct and indirect influence of information technology. Experts note that "The increase in the time spent in online communication leads to a decrease in the depth and intensity of direct communication and interaction with the loved ones 
and does not allow to establish deep emotional relationships in general (because they are difficult online). Nuances associated with facial expression, tone of voice, posture and gestures are no longer important and are being lost" [13]. Problems connected with excessive individualization are revealed. Live communication between teachers and students is reduced to a minimum, being replaced by communication in the form of "dialogue with a computer." This leads to the fact that "a student does not receive sufficient practice of dialogue, formation and formulation of thoughts in a professional language" [14].

Domestic and foreign researchers note that the serious problems of modern higher education associated with its Informatization are largely a consequence of the objective tendencies of social development and modern spiritual situation. Thus, R. Rapp-Wagner emphasizes the destructive impact of the use of postmodern ideas in Pedagogy, noting that they are characterized by "attack on the mind, rejection of the subject, denial of science, decomposition of values and relativism, gap between the European spiritual tradition and projects of Modern" [15]. In our opinion, A. P. Ogurtsov gave a fair critical assessment of postmodern atmosphere in modern education: "Postmodern ideologists of education stand for a radical school reform, for the rejection of the existing consensus on the aims and contents of education and training, for individualized training and application of psycho-technical tools for changing consciousness as of pupils, and of teachers. They advocate the interpretation of knowledge as a subjective construction, socio-psychological methods of values relativization and re-evaluation of the relationship "student-teacher". It all implies rejection of a teacher as a reputable specialist and educator" [16].

\section{CONTENT TRANSFORMATION OF TEACHING ACTIVITIES}

Changes in education initiated a trend of substantial transformation of a teacher's labor content. A new direction of teaching is developing robustly - the creation of electronic educational-methodical complexes, followed by the movement of most of the work with students in a telecom educational info system. Informatization of the educational process changes the interaction of a teacher with a student. It reduces the space of personal communication, which is now mediated by a computer. Currently, the formation of teacher IT-competency has become one of the most important tasks in the field of education. Loss of a teacher from today's educational chain, turning him or her into a "consultant", some kind of a tutor who develops a perfect individual learning scenario, is destructive for higher education: "There is no education outside personal interaction of a teacher and a student. There is imitation of some activity, there is payment for the relevant services, there is some diploma in the end, but there is no education" [17].

In general, educational realities show that the load on teacher has increased significantly. Due to the development and continuous updating of teaching programs for disciplines, funds of assessment tools, a variety of regular reports demanded from teachers there is too little time and energy for quality preparing for classes. This does affect the increase of professional deformation risk, and in some situations, it leads to neurotic breakdowns and even to the emergence of psychosomatic diseases, being some launching mechanism for them. It is obvious that at the present stage the profession of a teacher imposes special requirements to such an integral characteristic of the individual as stress resistance, because it refers to the most significant professional qualities of the teacher [18]. The experts say that teachers are at a high risk emerging of emotional burnout syndrome, as their activity is connected with great nervous and mental overload, intensive communication with people, frequent emotional stress, physical and mental exhaustion. We are talking about physiological factors (increased stress for visual and auditory analyzers, on a speech apparatus, etc.), and psychological (the lack of freedom to choose the object of work, the constant need to "keep in shape", keep strained, be careful; frequent focus switching; a large number of contacts, interpersonal conflicts, etc.) [19]. Special attention of scientists to the research of the problem related to the preservation and maintenance of psychoemotional health of teachers and improving their professional effectiveness is relevant and important for modern society, as it allows to understand better the causes of various professional changes, destructions, emotional burnout and predict occupational risks [20]. Psychological health of representatives of the pedagogical profession largely depends on the health of other subjects of the educational space.

\section{CONCLUSION}

The technological revolution in education is an objective process that is taking place in front of us. Like any complex social phenomenon, this sociocultural phenomenon is ambiguous. The system of education moves to new principles of functioning, where the main role belongs to Informatization. When working in computer networking profound qualitative changes in various activity components take place. The mechanisms for shaping these changes and their implications are almost unknown now. However, technocratic thinking, which is characterized by "primacy of the means over the purpose, goals over the meaning and universal interests, meaning over the existence and realities of the modern world, technology (including psychotechnics) over man and his values" [21], should not defeat. The formation of an overly rationalized and dehumanized type of social relations may be a serious problem, as it may be followed by the dismantling of the traditional society [22]. The development of information concepts in the education system should take into account these and other risks. It seems that one of the most important reasons for the problems of Informatization of education is to consider the means as a goal. The benefits of the new digital world are undeniable, but the main goal of education is to cultivate basic human values, to prepare a person who thinks independently and systematically. In our opinion, the introduction of electronic technologies in education is justified and appropriate only in the case when the use of a technology allows obtaining such results of training, when it is impossible to come without them. 


\section{REFERENCES}

[1] O.N. Arestova, L.N. Babanin, A.E. Voiskounsky, Communication in computer networks: psychological determinants and consequences. The Moscow University Herald. Ser. 14. Psychology. 1996, No. 4, pp. 14-20.

[2] V.A. Emelin, E.I. Rasskazova, A.S. Thostov, Technologies and identity: transformation of identification processes under the influence of technological progress. Modern researches of social problems (electronic scientific journal). 2012, No. 9(17).

[3] L.V. Cheremushkina, "The Influence of Internet-activity on mnemonic abilities of the subject". Psychology. Journal of Higher School of Economics, 2010, Vol. 7, No. 3, p. 58.

[4] D.V. Galkin, Problems of education in the context of Informatization: in search of a model of practical pedagogics. Humanitarian Informatics, 2005, No. 2, pp. 81-88.

[5] [5] A. Zapesotsky, Simulation of education or education of simulation? Higher Education in Russia. 2005, no. 7, p. 68.

[6] I.P. Berezovskaya, E.S. Novikova, Modern education: the Problem of influence of IT-activity on verbal intelligence. Scientific and technical sheets of St. Petersburg State Polytechnic University. Humanities and Social Sciences, 2016. Cyberleninka: https://cyberleninka.ru/article/n/sovremennoe-obrazovanie-problemavliyaniya-it-aktivnosti-na-verbalnyy-intellekt

[7] M. Spitzer, Antibrain: digital technology and the brain. 2014. Moscow: AST. 288 p., p. 65.

[8] M. Spitzer, pp. 64-65.

[9] S.I. Osipova, I.A. Baranova, V.A. Ignatova, Informatization of education as an object of pedagogical analysis, Fundamental Research, 2011, no. 12-3, pp. 508-509.

[10] T.S. Paniyotova, M.V. Mitrokhin, The Phenomenon of mobilographia as a new form of representation of identity. Knowledge. Understanding. Proficiency, 2016, No. 1, p. 150.

[11] S. Thomee, A. Harenstam, M. Hagberg, Mobile phone use and stress, sleep disturbances ad symptoms of depression among young adults - a prospective cohort study. BMC Public Health. 2011, no. 66, p. 11 URL: http://www.biomedcentral.com/1471-2458/11/66

[12] V.A. Emelin, E.I. Rasskazova, A.S. Thostov.

[13] V.A. Emelin, E.I. Rasskazova, A.S. Thostov.

[14] S.G. Grigoriev, V.V. Grinshkun, Informatization of education. Fundamentals: textbook for students of pedagogical universities and students of the system of advanced training of teachers, 2005. Moscow: MSPU, $241 \mathrm{p}$.

[15] R. Rapp-Wagner, Postmoderne Denken und Pädagogik: eine kritische Analyse aus philosophisch-anthropologischer Perspektive. Bern, Stuttgart, Wien, 1997, pp. 169-170.

[16] A. P. Ogurtsov, Antipedagogic: the challenge of postmodernism. Higher Education in Russia. 2002, no. 5, p. 84

[17] [17] A. Zapesotsky, p. 67.

[18] N.V. Soboleva, The problem of coping behavior and stress resistance in conditions of effective professional activity of teachers. Young Scientist. Psychology, 2016, No. 6 (110), p. 708.

[19] I.V. Sedova, Psychological factors of teachers' emotional burnout. RUDN Press, Series of Psychology and Pedagogy, 2014, No. 1, pp. $72-73$.

[20] N.E. Vodopyanova, Dysfunction of value-semantic regulation as risk factors for burnout syndrome and occupational health. Psychiatry, Psychotherapy and Clinical Psychology. 2011, No. 4, pp. 64-72.

[21] V.P. Zinchenko, E.B. Morgunov, "A Developing Man”, Essays on Russian Psychology. Moscow, 1994, p. 189.

[22] P.E. Rodkin, Irresistible mediator: the alienation of a man from the process of communication on the example of e-learning systems. Knowledge. Understanding. Proficiency, 2015, No. 4, pp. 204-211. 